not dead, and hallucinations of sight, as that she saw him in the room, when he had been buried some days. She became very suicidal, and was sent to the asylum. The delusions and hallucinations rapidly passed off, but were replaced by hysteria and incomplete epilepsy. The features of her case resemble so much those of the previous one that it is unnecessary to repeat them here. The somnambulism was not so marked in it, but the hysterical and epileptiform phenomena were more exaggerated than in the other one. Her attacks were most frequent and severe at the menstrual periods, and were sometimes ushered in by sickness and vomiting. She was also aphasic for some time after the attacks.

An interesting experiment was made regarding the hemianæsthesia Over the left anæsthetic arm a mustard-blister leaf was tied, and removed some hours afterwards, when the whole arm was found to be hyperæsthetic : while the right arm, which was previously extremely sensitive, had become almost completely anæsthetic. This transfer of sensibility, or " phenomenon of transfer", as it is called by Westphal, only lasted a few hours. The paralysis was benefited by the use of electricity ; but the relief was only temporary, and it returned after the next epileptiform attack.

As regards the treatment, ovarian pressure in the case of M. M. does not appear to have any effect in shortening the paroxysms, but it arrested at once the hysterical attacks of C. S., but did not influence the epileptiform seizures. Nitrate of amyl at once arrests the convulsions, but, when its administration is suspended, they recur, and the attack is only protracted. Metalloscopy has not yet been fully tried, though Westphal has recorded several cases, in which it has been used with success, in the Berliner Klinisch. Wochenschrift (No. 30, 1878). Considerable benefit has been got from the use of the monobromide of camphor. Aloes and iron, to restore the catamenial discharge, were found useful ; and, when the latter is thoroughly established, a favourable termination to the case, as regards its severer features, may be looked for.

\section{CASE OF AN DISTRIBUTION.}

By J. DRESCHFELD, M.D., M.R.C.P. Assistant.Physician, Manchester Royal Infirmary; Lecturer on Pathology,
Owens College.

THस following case is of interest chiefly on account of its distribution, while in its character it bears a close resemblance to the anæesthesia observed in hystero-epilepsy.

Ellen C., aged 28, came to the out-patient room, Manchester Infirmary, on July 3 rd, 1878 , complaining of numbness in her right leg and left side of trunk, from which she had been suffering for more than a month.

The following notes were then taken by Mr. James Wood, one of my clinical clerks.

Previous History. - The patient had always enjoyed good health, and had never suffered from convulsions or other nervous symptoms; had been married for twelve months, and was confined of her first child on May 14th, 1878. During the whole time of pregnancy, she suffered but little; the labour, however, was a very tedious one; the patient suffered from labour-pains for more than four days, and had eventually to be delivered by instruments. Two days after confinement, she got out of bed, when she fainted, and for four days afterwards she remained in an unconscious state. She had no fits during the time, but rambled very much. As soon as she regained consciousness, she was able to get about ; but suffered from giddiness and headache. She noticed also, at the same time, numbness of her left breast. She could not tell whether the "baby was suckling the left breast unless she looked". She noticed the numbness in her right leg also at the same time. Her appetite was but indifferent, and she suffered slightly from hæmorrhoids. The symptoms not abating, she eventually came to seek relief at the Infirmary.

Present Condition. - The patient was of middle stature, healthy-looking, and of a ruddy complexion. The examination of the organs of the chest and abdomen revealed nothing but normal relations. There was no disturbance of either motion or nutrition, and the abnormal phenomena which were observed involved the sensory sphere exclusively. A careful examination elicited the following interesting symptoms.

Special Sense Oroans: Vision normal on both sides; the fundus of both eyes normal; no achromatopsia. Hearing: Complete deafness on the left side; hearing on the right side normal. Smell: Complete absence of smell on the left side; smell on the right side normal. Taste: Normal on both sides. No anæsthesia of either side of face and neck. Trunk: Anæsthesia of the left side. The anæsthetic portion was bounded by the middle line, both in front and behind. Its upper margin was formed by a line passing horizontally round the left side, just above the third rib, and passing under the axilla to the middle line behind, while its lower border was bounded by a line commencing just above the pubes, and passing at first along Poupart's ligament and then horizontally round the left side (about one inch below the crest of the ilium) to the lowest part of the sacrum. Upper Extremities: Both were perfectly normal as regards sensibility and mobility. Lower Extremities: The left leg and thigh were perfectly normal both as regards motion and sensation; the right leg and thigh could be moved with perfect freedom, but were completely anæsthetic. The upper limit of the anæsthetic right lower extremity coincided exactly with the lower limit of the anæsthetic left half of the trunk, i.e., just where the patient began to feel tactile impressions on the right side there the anrsthesia on the left side commenced. There was no ovarian hyperæsthesia. Examining the character of the anæsthesia more minutely, the following points were made out.

I. Total loss of perception of tactile impressions in all the anæsthetic parts.

2. Analgesia of these parts. The right calf was transfixed by a large dissecting needle without the patient evincing the least sensation; the same needle was passed deeply into the left mamma and other parts of the left half of the trunk with the same result. The points where the needle was inserted bled freely.

3. Loss of muscular sense. The patient, with her eyes shut, had no knowledge of the relative position of the anæsthetic leg. She was told to sit down and shut her eyes, and, on now moving the right leg, she was still under the impression that the right foot touched the floor.

4. Loss of sense for temperatures ; neither cold nor heat was perceived by any of the anæsthetic parts. The sense for weights was not examined into.

On July 8th, the patient presented herself again, and her condition had undergone no change, and we now determined the behaviour of the anæsthetic parts to the electric current. On applying an induction current of moderate strength to the anæsthetic leg (one pole being placed in contact with the lumbar part of the spine, and the other with the calf of the right leg), the patient felt the current distinctly, and, on now increasing the strength of the current, the patient complained of a painful sensation, and distinct contraction was visible. We then tested the sensibility of a point in the left calf symmetrically situated with that on the right calf, to which the electrophone had been applied ; but the sensibility had remained the same, and, therefore, no transfer thad taken place. To the galvanic current the anæsthetic parts responded, though less distinctly than on the sound side.

Progress. - July roth. Ever since the application of the faradic current, the patient felt a slight return of sensibility, not only in the right leg, but also in the left half of the trunk. There was, however, still a considerable amount of dysæsthesia. The faradic current was now regularly applied by Mr. J. Wood, but only to the right leg, and with very satisfactory results ; for, on August 15 th, it was noted that the anæsthesia and analgesia had entirely disappeared from the right leg and left half of the trunk. Hearing and smell were still somewhat impaired on the left side, though a considerable improvement had taken place here too.

Since then, the patient presented herself once more, and reported that she was quite cured. A close examination showed still a slight affection of the organs of hearing and smell on the left side. The patient experienced, however, so little discomfort from this, that she was unwilling to submit to further treatment.

Before concluding this brief sketch, it may be of interest to state that lactation was in no way interfered with, and that the left mamma yielded quite as much milk as the right.

REMARKS. - The case presents several peculiarities. I. The distribution of the anæsthesia is, as far as I can make out, unique. Briquet describes several cases of hysteria with alternating anæsthesia ; but, in all these cases, the whole of one side of the trunk and the opposite side of the face were so affected, and the same distribution has been observed in cases of anæsthesia dependent on organic lesions (Gazette Hebdom., 1878, Nos. I and 3). Again, I believe, in all cases of hysteroepilepsy described, the anæsthesia observed was distinctly unilateral, affecting the sense organs, the trunk, and the extremities of the same side. The integrity of the upper extremity of the face and neck, of vision, and of the sense of taste in this case is equally remarkable.

2. In its character the case very much resembles cases of hysteroepilepsy ; but here the absence of other hysterical symptoms, especially the absence of any hystero-epileptic attack, will again be remarked, unless we consider the attack of unconsciousness which took place soon after the confinement as a kind of trance or comatose condition, not unlike that observed in a case recently published by Vigoureux. (Pros. Médic., 1878, page 679.) The sudden seizure and the fact that 
thetpatient whas able to get about as soon as she regained-consciousness: make.this, vien highly probable.

3. Thermarked effect of the application of the electric, current, and the.permanent cure-effected by it, which distinguish this case again from tho ordinary cases of hystero-epilepsy, prevented us from trying experiments with metals or magnets, which, in the hands of Professor Charcot, have given such interesting results now well known to the readers of the BRITISH MEDICAI Journal.

\section{ON A CASE OF HYSTERIA, SIMULATING CHOREA.}

By CORDLEX BRADFORD, M.R.C.S.Eng., Smethwick.

M. T., AGED 19, was admitted into the Queen's Hospital, Birmingham, under the care of Dr. Sawyer, during my tenure of the office of housephysician, complaining of pain in the lower part of her back and with general jerking movements of the muscles of her body. She stated that it came on suddenly four days ago, whilst standing at the house-door talking to her uncle, with whom she lived. It affected her left side only at first, but soon became general. She saw a surgeon, who told her she was suffering from St. Vitus's dance. In the previous history, the important fact was noticed, that a few months since, she had been to Bath, and there seen her cousin in the hospital suffering from true ohorea. She had always been healthy, and, except the above, no cause could be found for her present attack.

On admission, there were persistent irregular movements of both upper and lower extremities. There was no affection of the facial or lingual muscles. The movements of inspiration and expiration were irregular and jerking in character. The movements were only slightly, if at all, increased by putting the affected muscles into action. After being made to stand for about five minutes, the movements became somewhat wcrse; she burst out crying, and would have fallen had not some one caught hold of her. She was put in a room alone, to see if the movements would cease when she was alone; but, on looking through the key-hole, they were seen to be continuing the same as before. On examining the spine, it was found to be quite normal ; but she complained of pain on firm pressure over the spines of the third and fourth Jumbar vertebræ, and, on this being repeated, she invariably complained of pain in the same place. The passage of a hot sponge and a piece of ice gave her no pain, but the latter temporarily arrested the movements. There did not appear to be any impairment of sensation in any part of the body. There was pain on superficial and deep pressure over the position of the left ovary. The cardiac and pulmonary organs were healthy. Prolonged and firm pressure over the position of the-left ovary, as marked out by M. Cbarcot in his lectures, published by the New Sydenham Society, was at first tried, with the effect of arresting the movements; but, as soon as the pressure was removed, the movements returned as: bad as ever. One pole of a single-celled interrupted current (Stöhrer's) battery was applied to the back of the neck, and the other over the sacrum. In a short time (a couple of minutes), the movements completely ceased ; but, on removing the poles, they were seen to be commencing again in the fingers and toes. The battery was, therefore, reapplied ; this time, one pole being applied over the sacrum and the other over the left ovary, and then to either arm. The movements soon ceased, and did not return. She was then told she was quite well, but, should she be troubled with them again, the battery would have to be applied much more strongly and for a longer time. In half an hour, she was told to get up and walk round the ward, which she did quite well. She slept comfortably during the night, and, the next morning, was discharged cured.

REMARKS. - The diagnosis of this case was founded chiefly upon the following facts . the entire freedom from implication of the facial and lingual muscles-especially the latter-which are almost invariably the first and last affected in true chorea, and the knowledge of her having been to Bath, and there seen her cousin, who was really suffering from the true disease; although we could not discover any cause for the attempted imposition, as she appeared to have a very comfortable home and to be well treated by her uncle, and to whom she willingly returned on leaving the hospital. These facts were also strengthened considerably by the marked tenderness over the position of the left ovary. The result of the treatment fully confirmed the diagnosis, that it was a case of hysteria and not chorea.

With regard to the treatment, it is worthy of remark that the continued firm pressure over the ovary arrested the movements temporarily only, for, as soon as this pressure was removed, they returned as bad as ever. Whether this temporary arrest was due to compression of the ovary, or whether it was due to the pain of the compressed body, I am at a loss to say.

\section{ABSTRACT OF INTRODUCTORY LECTURE TO THE}

\section{COURSE OF CIINICAL SURGERY IN UNIVERSITY COLLEGE HOSPITAL,}

Delivered on October 7 th, 1878 .

\section{BY CHRISTOPHER HEATH, F.R.C.S.Eng.,} Holme Professor of Clinical Surgery.

THE study of disease at the bedside is necessarily analytical. The. patient being placed before the practitioner, it is for him to find out what is the disease or injury which is interfering with. health before he can apply his remedies. He must analyse the various symptoms, discarding those which have apparently no bearing upon the sources of discomfort, and following up those clues which the careful investigation of other symptoms affords. To treat symptoms alone without tracing them to their source is as bad a practice as to trace out symptoms to an accurate diagnosis and then leave the patient without treatment ; for, after all, it is the living patient who demands our aid, and not the symptoms of the disease, as might be imagined were the surgeon to depend upon books alone for surgical knowledge.

The information to be found in surgical works is most valuable, if properly employed, but it cannot replace bedside experience. Systematic lectures and treatises must necessarily give an account of the pathology, symptoms, and treatment of a typical case, and these "classical" descriptions are of great use as standards, from which, however, all degrees of variation must be looked for. These descriptions are for the most part synthetical, the symptoms being massed together in the order thought most convenient; whilst in the living body the symptoms do not follow but accompany one another with more or less jostling and intermingling. If each disease wrote its name or its num. ber legibly upon the patient, it would be easy to turn to the appropriate page in a surgical treatise and find ont all about it; but clinical study alone will enable the surgeon to recognise disease or injury as readily as if its name were in truth "writ large". It is, indeed, often amusing to note how a well read student who has failed entirely to recognise a disorder will, when once he has learned its name, discuss glibly its pathology and treatment. To appreciate thoroughly deviations from the normal standard of health, it is necessary to be fully acquainted with the anatomy of the human frame, and hence the advantage of pursuing the study of anatomy before beginning that of surgery. Minute details of anatomy which may be useful as mere examination tests will doubtless escape the memory; but broad facts, if duly impressed by actual manipulation and dissection, will remain for life to constitute that "working knowledge" which is the practitioner's capital. A knowledge of physiology and chemistry is necessary both for the explanation and testing of certain morbid phenomena, and the study of pathology explains the morbid changes recognised in the living and found in the dead body.

The objects we have before us are that every member of the class shall so learn to use his senses of sight, touch, hearing, and possibly smell, that he may have it in his power to evolve from his brain a happy synthesis or diagnosis built upon the evidence communicated by his several senses. Of course, both senses and brains differ, and, as one man is short-sighted, so another may be small-brained; but both brain and senses will repay cultivation. The eye must be educated to accuracy in estimating slight deviations from the natural form, and in the recognition of appearances which have been previously seen. The ear must learn to disregard the gabble of garrulous patients and pick out the facts which are really sought for, besides being educated to distinguish morbid sounds within the human body. The fingers must learn to appreciate slight variations in consistency, in size, and in contour, if they are to be useful in diagnosis; and they must be educated to obey the surgeon's will and perform complicated movements like automata, if they are ever to make up the traditional "surgeon's hand". Instruments of precision are now in every tyro's hands; but thermometers and all the "'scopes" together, useful as they are, will never supersede, however much they may aid, bedside experience of disease and the use of the senses. Not least among these must be reckoned that "common sense" which is so uncommon, which keeps its happy possessors out of difficulties, and smoothes their path to success as practitioners, and even this is to be cultivated and learned by study of mankind, both healthy and diseased, and both within and without the hospital.

But the brain must not be forgotten ; for upon it the diagnosis, prognosis, and treatment will depend. Men's brains seem to work at dif- 